\title{
The CENTURY Model as a Tool to Study Soil Carbon Dynamics of Coconut Ecosystem in the Western Zone of Tamil Nadu, India
}

\author{
P. Lincy Davis*, S. Panneerselvam, K.S. Subramanian, S. Sandeep, \\ Balaji Kannan, N. Shoba and H.P. Maheswarappa \\ Agro Climatic Research Centre, Tamil Nadu Agricultural University, \\ Coimbatore, Tamil Nadu, India \\ *Corresponding author
}

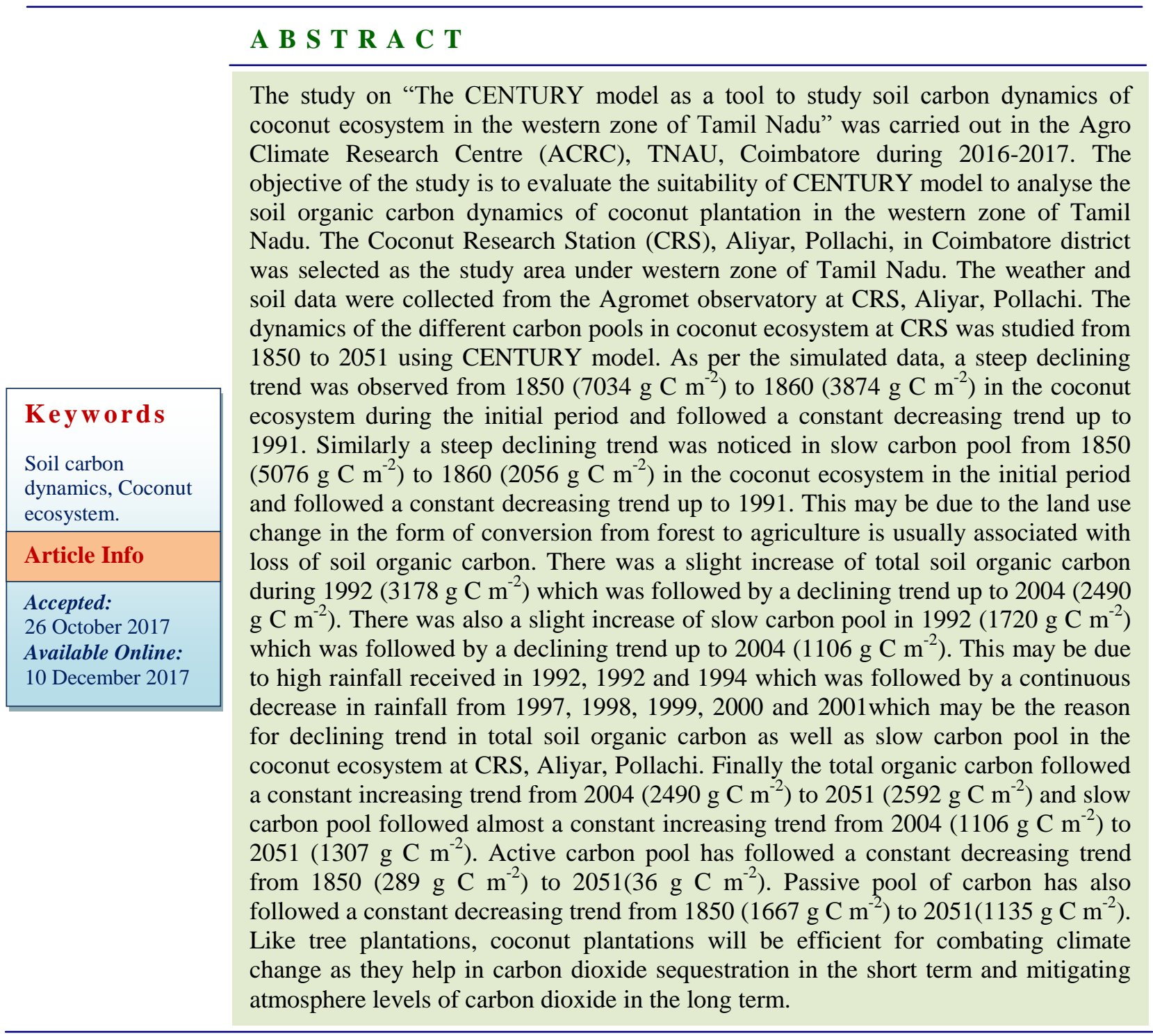




\section{Introduction}

Carbon is present throughout the natural environment in a fixed amount. It takes many forms and moves through the environment via the carbon cycle. The circulation and transformation of carbon back and forth between living things and the environment is called carbon cycle. Carbon travels through the atmosphere, lithosphere, hydrosphere, and biosphere and thus represents one of Earth's primary biogeochemical cycles.

At global level, 81 per cent of the carbon in the earth's biosphere is stored in soil. Carbon is a vital component of soil organic matter (SOM), created by cycling of organic compounds in plants, animals and microbes into the soil. The global pool of SOM is estimated to contain about $1500 \mathrm{Pg}$ of carbon to 1 metre depth (Batjes, 1997). Soil carbon sequestration means the capture and long term storage of carbon in soil. So there is a reduction in carbon dioxide emission which has a substantial impact on long term opportunities to stabilize global warming and mitigate the impact of climate change. Due to the enhanced decomposition rate under high moisture and temperature, SOM and other organic compounds show a faster turnover in tropics compared to temperate soils.

Lal (2008) observed that the soil organic carbon concentration of India is severely depleted, and is below the critical limits for soil and ecosystem functions. The soils of India have lower soil organic carbon (SOC) pool and their capacity as determined by the climate and ecological factors; there is a large capacity for atmospheric carbon dioxide $\left(\mathrm{CO}_{2}\right)$.

Climate change poses the single most important threat to the future of food production and security. The changes needing attention includes temperature, precipitation, sea level rise and atmospheric $\mathrm{CO}_{2}$. So the future research should help in designing special programmes for adaptation to climate change (Swaminathan, 2008). New research initiatives and action to deal with the concerns on soil quality for sustaining environmental integrity and soil quality as part of other natural resources and its role in human health have to be considered (Katyal, 2008).

The understanding of the different soil $\mathrm{C}$ pools and processes are of vital importance before the implementation of agro-ecological management practices, as it determines the success of SOC management (Srivastava et al., 2016). Measurements of SOM or soil organic carbon (SOC) in an ecosystem alone reveal little about how carbon has changed in the past or will change in the future. But to predict the effect of climate and land-use change need accurate dynamic models. Primary production (input) and decomposition (output) are two main primary processes which control soil carbon storage.

Models were evaluated in terms of their ability to simulate observed soil carbon changes. Numerous studies and evaluation of simulation models have been reported. Among those models, CENTURY is the model most widely used and tested. CENTURY has been developed to simulate carbon and nutrient dynamics on monthly time steps for an annual cycle over time scales of centuries and millennia. Scientifically prepared models with different parameters will be very much helpful in generating future climatic scenarios that are related to soil carbon dynamics of coconut ecosystems.

Hence, the present investigation was taken up with the following objective to evaluate the suitability of CENTURY models for carbon turnover predictions in coconut ecosystems of tropics. 


\section{Soil carbon dynamics}

Soil carbon dynamics comprise the study of the soil $\mathrm{C}$ pools, the rate of its exchange among them (turnover) and the associated regulatory variables (Trumbore, 2009). This was slightly modified (Therefore, it encompasses the kinetics as well as the governing variables, which defines the temporal change in SOC pools among its various compartments. SOC dynamics generally shows a non-linearity, and several years are required to reach a new equilibrium (Luo et al., 2004). Therefore, the short-term assessments misrepresent the SOC dynamics.

However, the long-term datasets to derive the rate of change across the various SOC pools to better understand the SOC dynamics are often scarce (Vaccari et al., 2012). The depletion of the SOC pool leads to a downfall in the soil quality and productivity (Lal, 2001). SOC consists of several pools, namely active, slow and passive, with differential turnover rate ranging from months to over several hundred to thousands years (Silveira et al., 2008). The details are given below.

Active SOC pool, also called labile form of C, is primarily made up of fresh plant and animal residues that breakdown in a very short time, from a few weeks to a few years. This kind of organic matter is associated with a lot of biological activity.

Passive SOC pool, also known as humus or nonlabile form of $\mathrm{C}$, is not biologically active, and thus it provides very little food for soil organisms. It may take hundreds or even thousands of years to fully decompose. It is a dark, complex mixture of significantly transformed organic substances which also contains substances synthesized by the soil organisms. Usually, humus represents the majority of soil organic matter (SOM), and it is relatively stable over time.
Slow SOC pool is somewhere in between active and passive SOM. It consists primarily of detritus (i.e., partially broken down cells and tissues), which decomposes gradually. Slow SOM is somewhat resistant to decay than active pools and may take a few years to a few decades to breakdown completely. In general, the turnover rate of labile $\mathrm{C}$ pool ranges from several weeks to months or years, whereas recalcitrant, non-labile pools have a turnover rate of centuries to millennia.

\section{Materials and Methods}

The present investigation was taken up by Agro Climatic Research centre (ACRC), TNAU, Coimbatore to evaluate the suitability of CENTURY model to analyse the soil carbon dynamics of the coconut ecosystem in the Western zone of Tamil Nadu. The Coconut Research Station (CRS), Aliyar, Pollachi, in the Coimbatore district was selected as the study area under western zone of Tamil Nadu.

The weather data were recorded from the Agromet observatory at CRS, Aliyar. The soil data as well as management practices followed were also collected from CRS, Aliyar. The dynamics of the different carbon pools in coconut ecosystem at CRS, Aliyar was studied from 1850 to 2051 using CENTURY model.

\section{Estimation of soil carbon dynamics using models}

The primary purposes of the model are to provide a tool for ecosystem analysis, to test the consistency of data and to evaluate the effects of changes in management and climate on ecosystems. Evolution of the model will continue as our understanding of biogeochemical processes improves. In depth understanding of labile soil organic carbon pool is necessary to define the soil health and 
nutrient turnover, since it plays an important role in short term $\mathrm{C}, \mathrm{N}$ cycles and climate change (Katyal, 2015).

Model will be very much helpful tool in estimating the soil carbon dynamics of an ecosystems. Measurements of SOM or soil organic carbon (SOC) in an ecosystem alone reveal little about how carbon has changed in the past or will change in the future. But to predict the effect of climate and land-use change need accurate dynamic models. Primary production (input) and decomposition (output) are two main primary processes which control soil carbon storage. Models were evaluated in terms of their ability to simulate observed soil carbon changes. Numerous studies and evaluation of simulation models have been reported. Among those models, CENTURY model is most widely used.

\section{CENTURY model}

CENTURY has been developed to simulate carbon and nutrient dynamics on monthly time steps for an annual cycle over time scales of centuries and millennia. The program "CENTURYM" is a FORTRAN representation of the CENTURY SOM model which was developed by Parton et al., (1987, 1988). It simulates $C, N, P$, and $S$ dynamics through an annual cycle to centuries and millennia. The CENTURY Model Version 4.0 embodies our best understanding to date of the biogeochemistry of Carbon, Nitrogen, Phosphorus, and Sulphur.

\section{Data requirement of CENTURY model}

This model requires weather parameters such as monthly maximum and minimum temperature and monthly rainfall. In addition to that, it requires twelve data files (Table 1). Each file contains a certain subset of variables. Within each file, there may be multiple options in which the variables are defined for multiple variations of the event. For example, within the cult.100 file, there may be several cultivation options defined such as ploughing or sweep tillage, thinning operations etc. For each option, the variables are defined to simulate that particular option. Each data input file is named with a ".100" extension to designate it as a CENTURY file. These files can be updated and new options created through the FILE.100 program.

\section{Weather parameters}

The primary dataset like monthly weather data of rainfall, maximum and minimum temperature (1990-2016) were collected from the Agromet Observatory, Coconut Research Station (CRS), Aliyar, Pollachi, Coimbatore. Normal Rainfall, Maximum Temperature and Minimum Temperature were worked out (Fig. $2 \mathrm{a}$ and 2b). Rainfall pattern of CRS, Aliyar is also worked out (Fig. 3) from 1990 to 2016.

\section{Structure of the model}

This SOM model includes three soil organic matter pools (active, slow and passive) with different potential decomposition rates, above and below ground litter pools and a surface microbial pool which is associated with decomposing surface litter. The active pool [SOM1C(2)] represents soil microbes and microbial products (total active pool is 2 to 3 times the live microbial biomass level) and has a turnover time of months to a few years depending on the environment and sand content.

The soil texture influences the turnover rate of the active soil SOM (higher rates for sandy soils) and the efficiency of stabilizing active SOM into slow SOM (higher stabilization rates for clay soils). The surface microbial pool [SOM1C (1)] turnover rate is independent of soil texture, and it transfers 
material directly into the slow SOM pool (SOM2C). The slow pool includes resistant plant material derived from the structural pool and soil-stabilized microbial products derived from the active and surface microbial pools. It has a turnover time of 20 to 50 years. The passive pool (SOM3C) is very resistant to decomposition and includes physically and chemically stabilized SOM and has a turnover time of 400 to 2000 years. The proportions of the decomposition products which enter the passive pool from the slow and active pools increase with increasing soil clay content.

\section{Running of the model}

The site data (location) and site specific parameters were collected and create site.100 file. Then the site specific event options such as crop, cultivation, fertilizer, fire, etc. were created in the Event. 100 file (Fig. 1). Along with that, the schedule file which determines the order and types of events was created. After that the simulation was kept ready to run.

\section{Results and Discussion}

The dynamics of the different carbon pools in coconut ecosystem at CRS was studied from 1850 to 2050 using CENTURY model. As per the simulated data, a steep declining trend was observed from $1850\left(7034 \mathrm{~g} \mathrm{C} \mathrm{m}^{-2}\right)$ to
1860 (3874 $\mathrm{g} \mathrm{C} \mathrm{m}^{-2}$ ) in the coconut ecosystem during the initial period and followed a constant decreasing trend up to 1991. Similarly a steep declining trend was noticed in slow carbon pool from $1850\left(5076 \mathrm{~g} \mathrm{C} \mathrm{m}^{-2}\right)$ to $1860\left(2056 \mathrm{~g} \mathrm{C} \mathrm{m}^{-2}\right)$ in the coconut ecosystem in the initial period and followed a constant decreasing trend up to 1991 (Fig. 4a and $b$ ). This may be due to the land use change in the form of conversion from forest to agriculture is usually associated with loss of soil organic carbon. Houghton et al., (1983) indicated that transforming forest into crop land reduces soil organic carbon densities substantially as similar to the above study.

There was a slight increase of total soil organic carbon during 1992 (3178 g C m$^{-2}$ ) which was followed by a declining trend up to 2004 (2490 $\mathrm{g} \mathrm{C} \mathrm{m}^{-2}$ ). There was also a slight increase of slow carbon pool in $1992(1720 \mathrm{~g}$ $\mathrm{C} \mathrm{\textrm {m } ^ { - 2 }}$ ) which was followed by a declining trend up to 2004 (1106 $\mathrm{g} \mathrm{C} \mathrm{m}^{-2}$ ) (Fig. 4c). This may be due to high rainfall received in 1992, 1992 and 1994 which was followed by a continuous decrease in rainfall from 1997 , 1998, 1999, 2000 and 2001which may be the reason for declining trend in total soil organic carbon as well as slow carbon pool in the coconut ecosystem at CRS, Aliyar, Pollachi (Fig. 3).

\section{Fig.1 The CENTURY model environment}

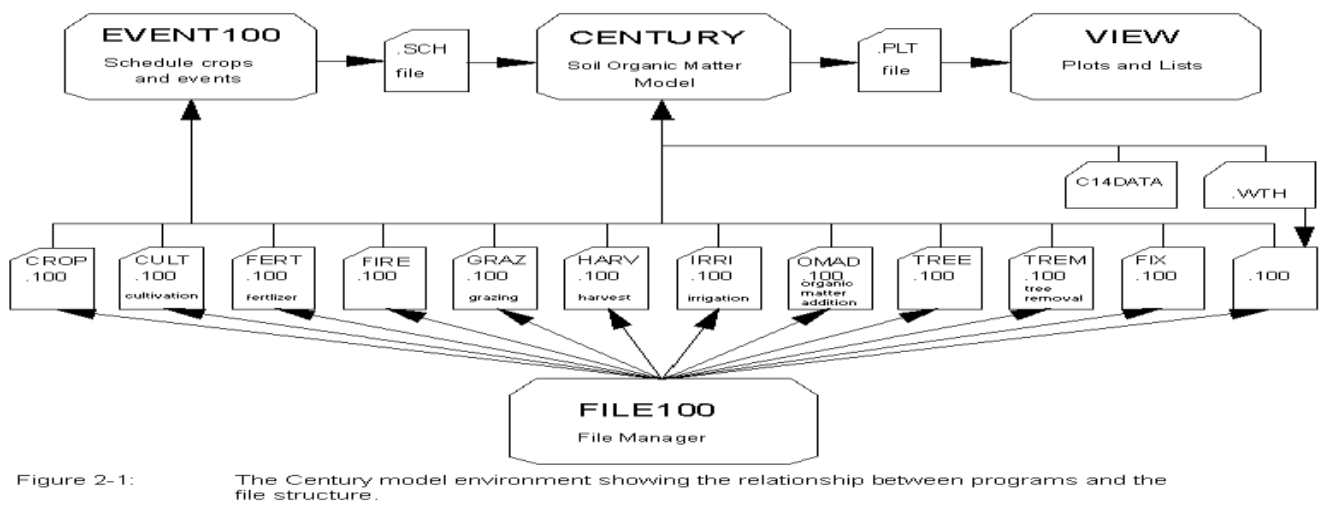


Fig.2a Normal rainfall of CRS, Aliyar, Pollachi, Coimbatore

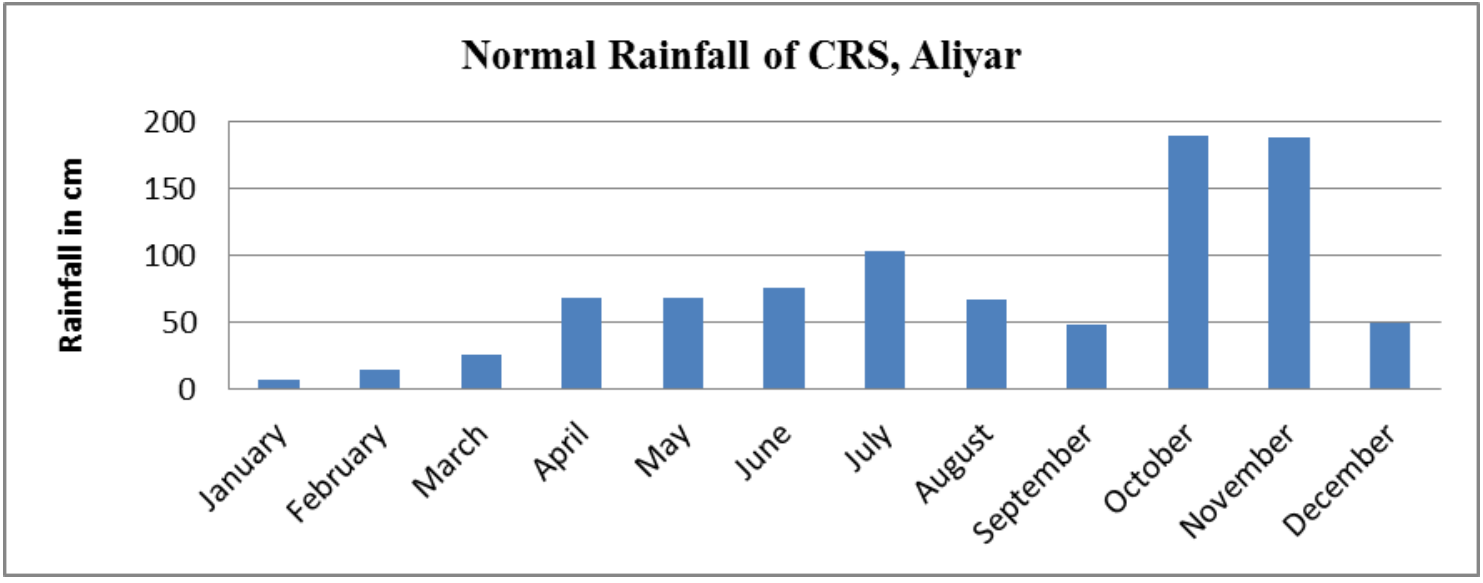

Fig.2b Normal temperature of CRS, Aliyar, Pollachi, Coimbatore

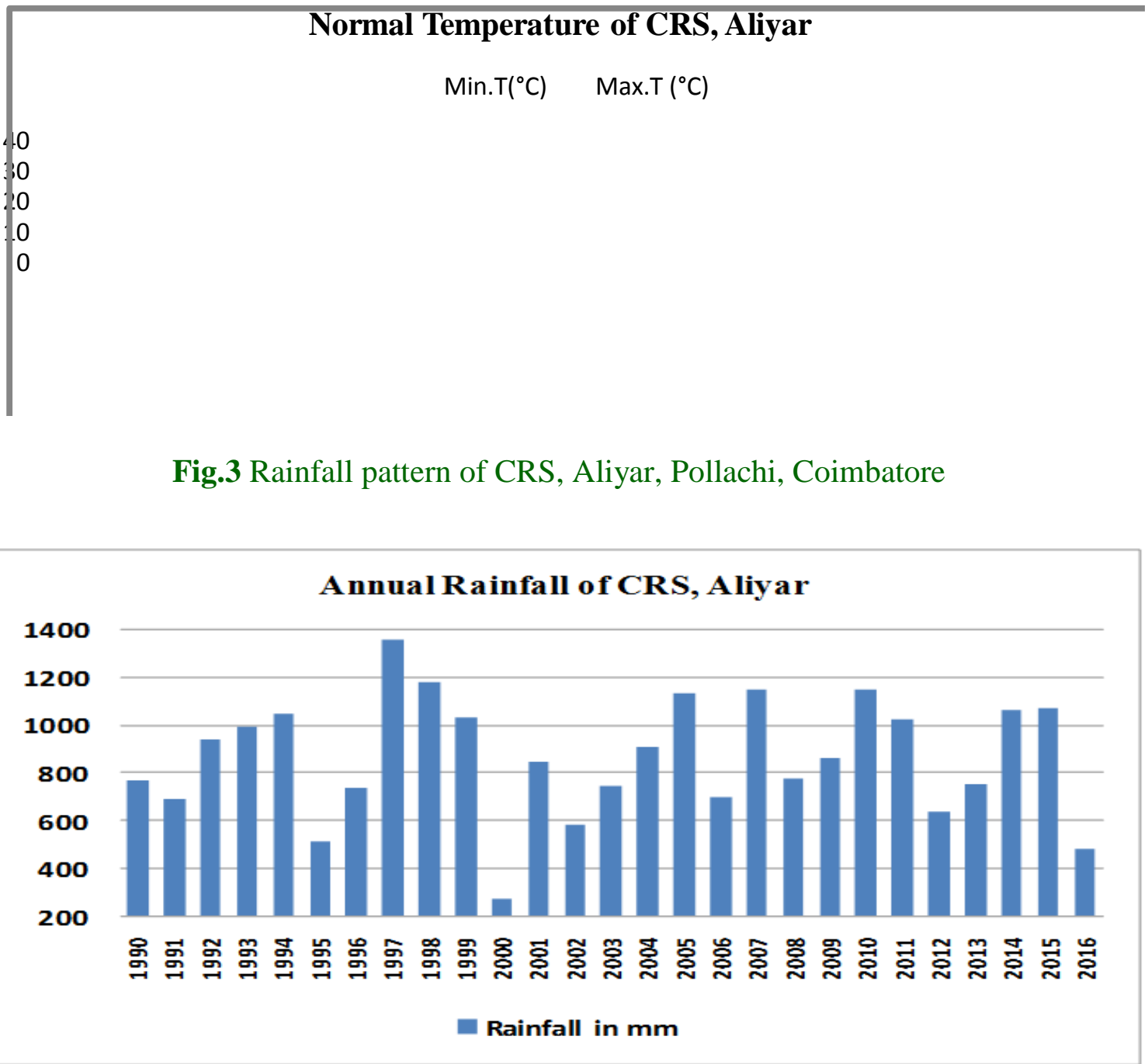


Fig.4a Soil carbon dynamics of coconut plantation, CRS, Aliyar from 1850 to 1900

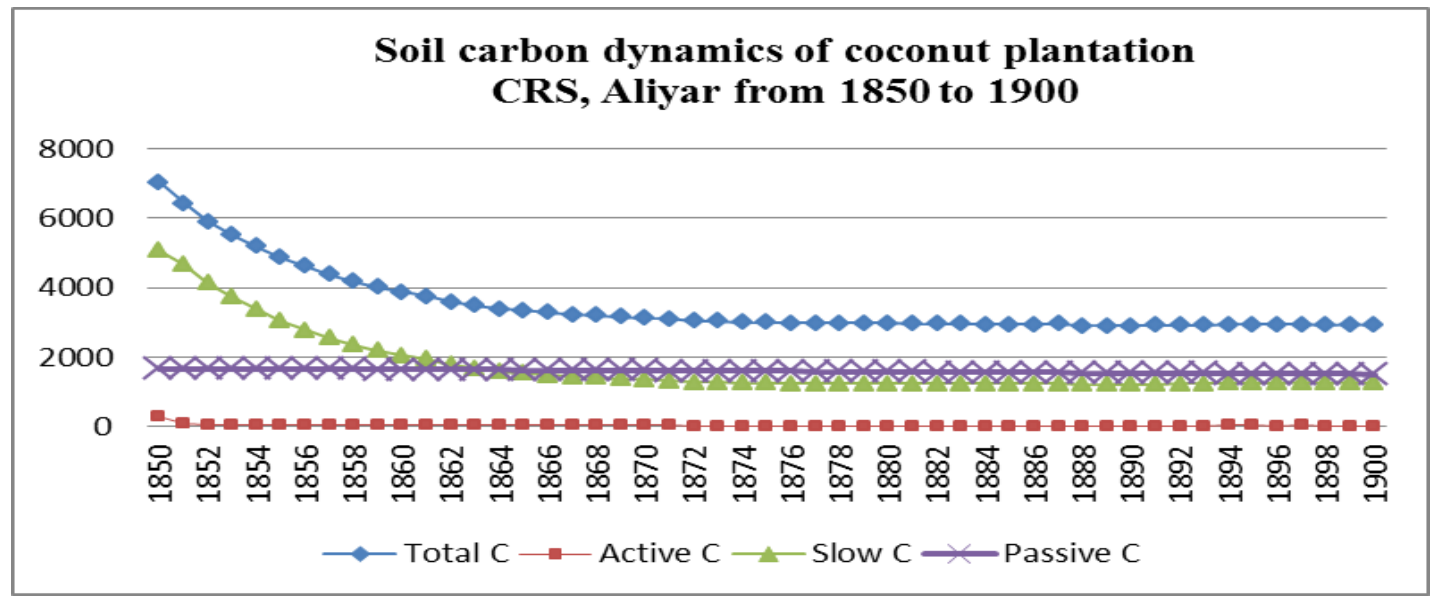

Fig.4b Soil carbon dynamics of coconut plantation, CRS, Aliyar from 1900 to 1950

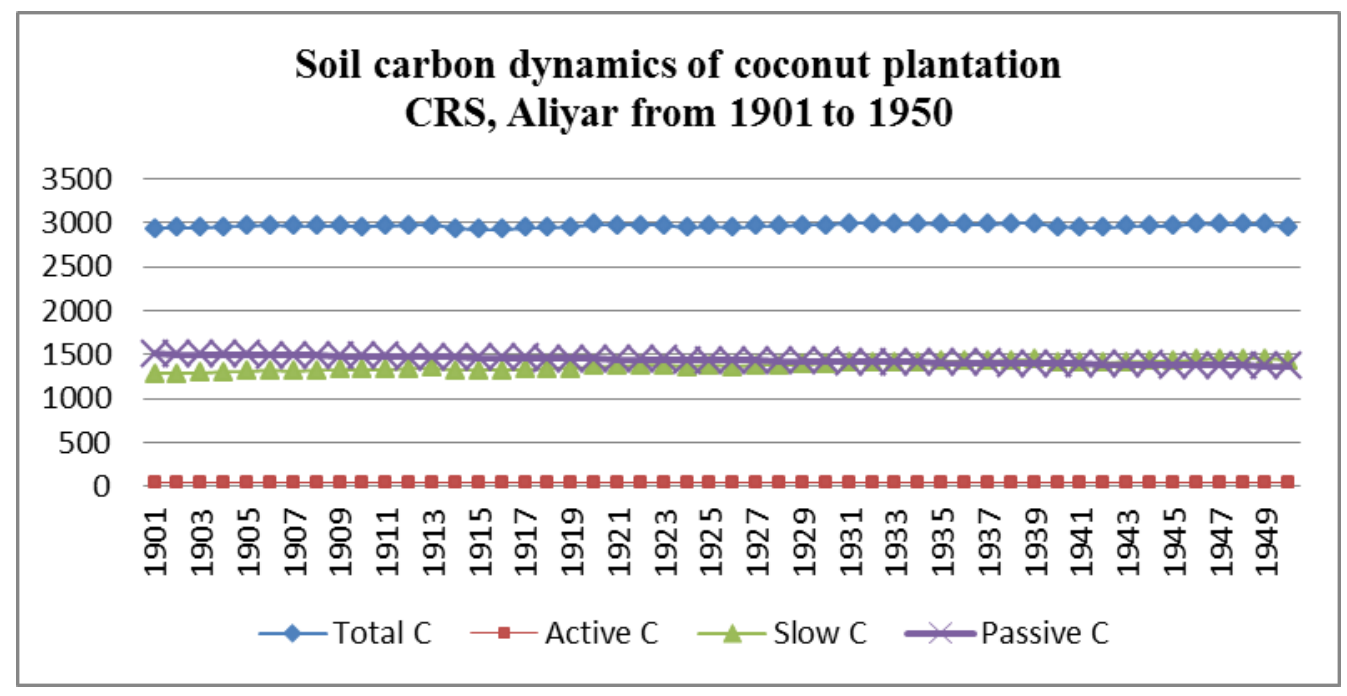

Fig.4c Soil carbon dynamics of coconut plantation, CRS, Aliyar from 1950 to 2000

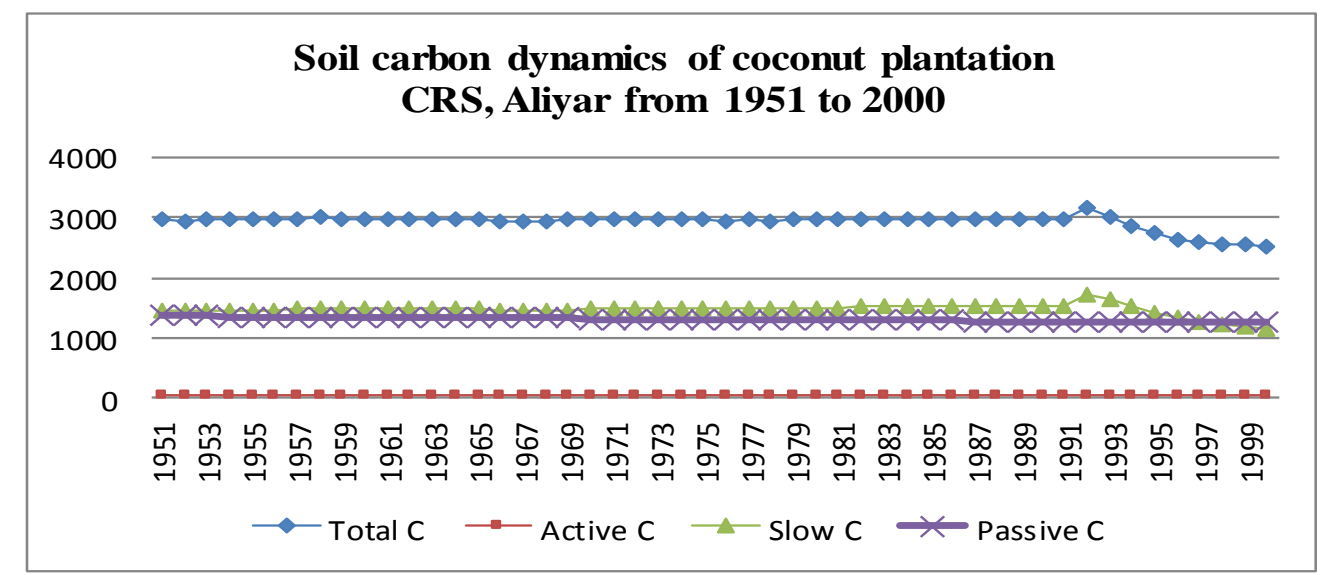


Fig.4d Soil carbon dynamics of coconut plantation, CRS, Aliyar from 2000 to 2050

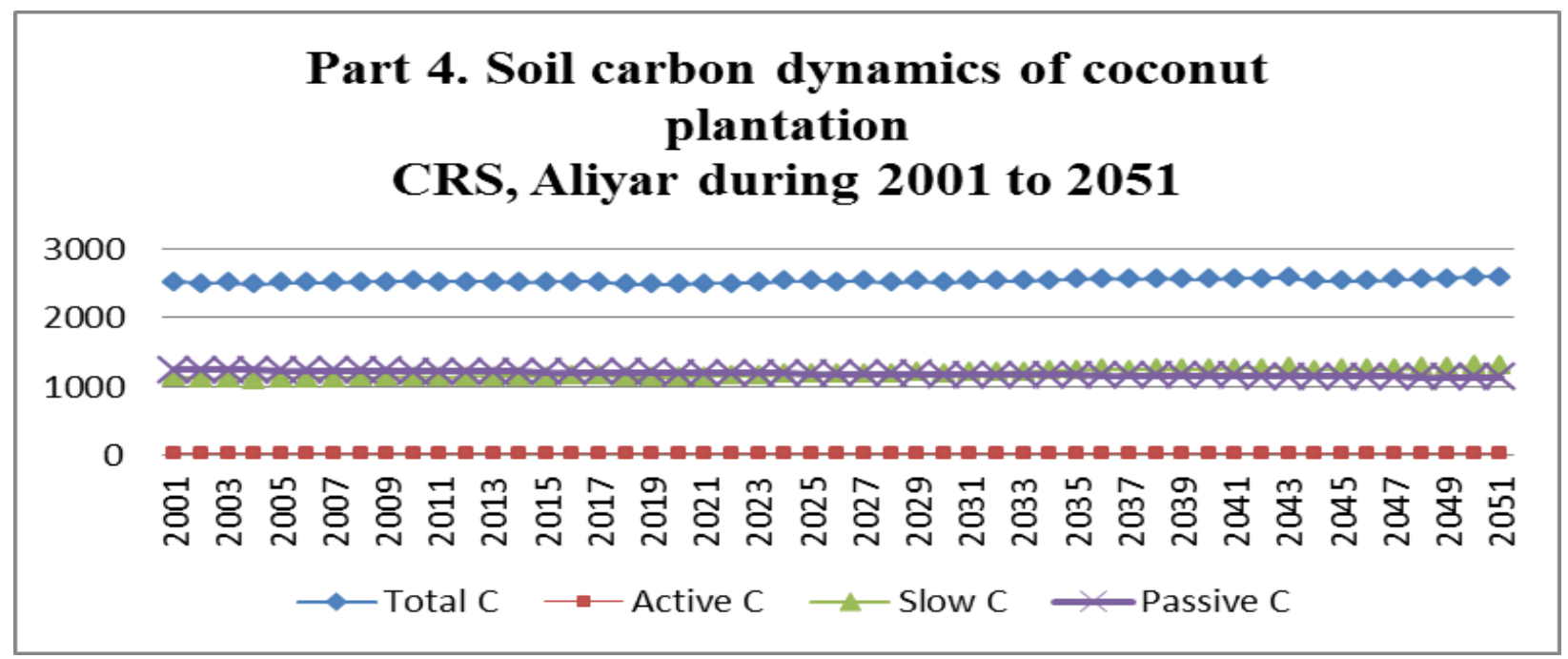

Fig.5 Soil carbon dynamics of coconut plantation, CRS, Aliyar from 1850 to 2051

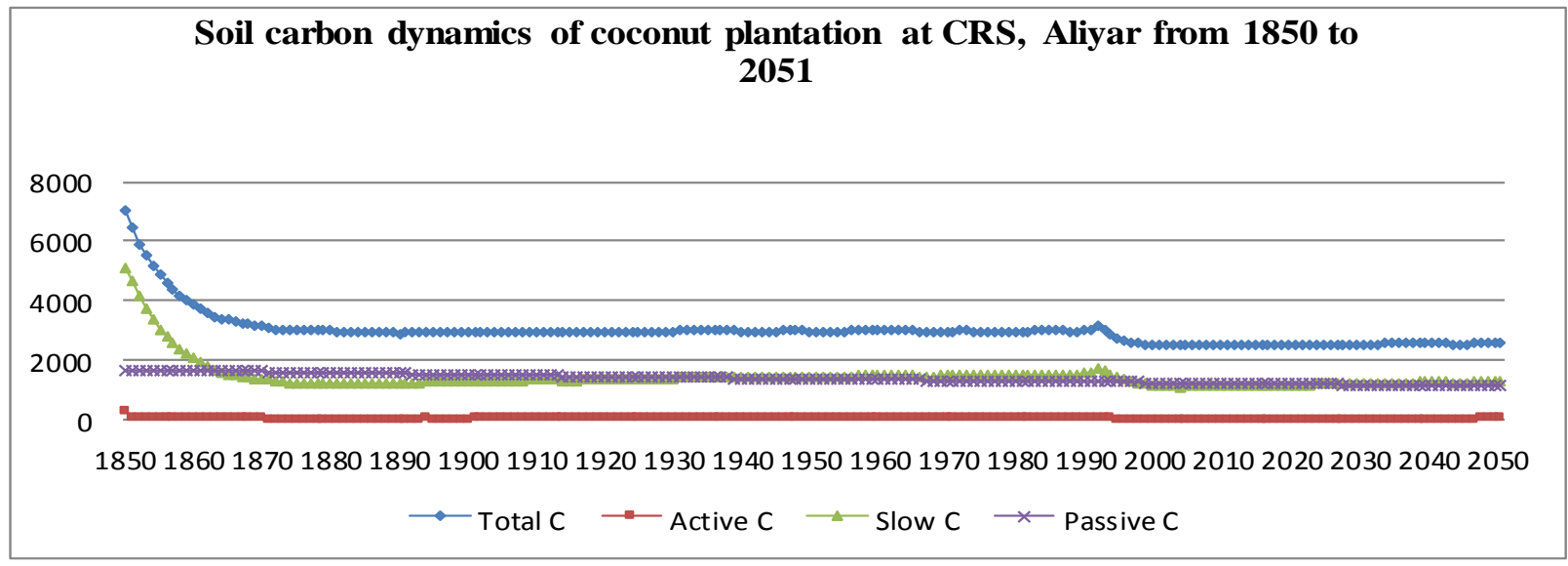

Table.1 Files used in CENTURY model

\begin{tabular}{|l|l|l|}
\hline 1 & fix.100 & $\begin{array}{l}\text { File with fixed parameters primarily relating to organic matter decomposition and not } \\
\text { normally adjusted between runs }\end{array}$ \\
\hline 2 & site. 100 & $\begin{array}{l}\text { Site-specific parameters such as precipitation, soil texture, and the initial conditions } \\
\text { for soil organic matter; the name of this file is provided by the user }\end{array}$ \\
\hline 3 & crop. 100 & Crop options file \\
\hline 4 & cult.100 & Cultivation options file \\
\hline 5 & fert.100 & Fertilization options file \\
\hline 6 & fire. 100 & Fire options file \\
\hline 7 & graz. 100 & Grazing options file \\
\hline 8 & harv.100 & Harvest options file \\
\hline 9 & irri.100 & Irrigation options file \\
\hline 10 & omad.100 & Organic matter addition options file \\
\hline 11 & tree.100 & Tree options file \\
\hline 12 & trem.100 & Tree removal options file \\
\hline
\end{tabular}


Table.2 Dynamics of soil organic carbon pools in coconut ecosystem

\begin{tabular}{|r|r|r|r|r|}
\hline \multicolumn{1}{|r|}{ Time } & Total C & Active C & \multicolumn{1}{c|}{ Slow C } & \multicolumn{1}{c|}{ Passive C } \\
\hline 1850 & 7034.32 & 288.56 & 5076.18 & 1666.57 \\
\hline 1860 & 3874.437 & 45.343 & 2055.506 & 1650.464 \\
\hline 1870 & 3122.676 & 35.006 & 1353.884 & 1616.445 \\
\hline 1880 & 2983.032 & 34.465 & 1249.13 & 1580.828 \\
\hline 1890 & 2903.165 & 33.501 & 1216 & 1545.753 \\
\hline 1900 & 2915.881 & 34.175 & 1262.369 & 1511.797 \\
\hline 1910 & 2956.036 & 35.903 & 1327.845 & 1480.737 \\
\hline 1920 & 2977.086 & 38.163 & 1366.031 & 1450.671 \\
\hline 1930 & 2975.007 & 37.713 & 1397.326 & 1421.205 \\
\hline 1940 & 2947.97 & 37.291 & 1404.938 & 1394.679 \\
\hline 1950 & 2954.681 & 38.044 & 1435.23 & 1367.85 \\
\hline 1960 & 2992.605 & 39.15 & 1482.954 & 1343.366 \\
\hline 1970 & 2959.077 & 39.53 & 1481.568 & 1319.23 \\
\hline 1980 & 2964.689 & 40.148 & 1505.89 & 1296.068 \\
\hline 1990 & 2979.47 & 40.484 & 1542.483 & 1275.102 \\
\hline 2000 & 2528.192 & 31.039 & 1159.645 & 1250.831 \\
\hline 2010 & 2535.227 & 32.757 & 1149.375 & 1225.841 \\
\hline 2020 & 2482.272 & 31.781 & 1136.217 & 1201.631 \\
\hline 2030 & 2509.304 & 32.516 & 1189.779 & 1178.307 \\
\hline 2040 & 2561.544 & 34.317 & 1259.146 & 1157.184 \\
\hline 2050 & 2597.099 & 36.68 & 1302.969 & 1136.871 \\
\hline & & & & \\
\hline
\end{tabular}

Finally the total organic carbon (Fig. 4d) followed a constant increasing trend from 2004 (2490 $\mathrm{g} \mathrm{C} \mathrm{m}^{-2}$ ) to $2051\left(2592 \mathrm{~g} \mathrm{C} \mathrm{m}^{-2}\right)$ and slow carbon pool followed almost a constant increasing trend from 2004 (1106 g $\mathrm{C} \mathrm{m}^{-2}$ ) to 2051 (1307 $\mathrm{g} \mathrm{C} \mathrm{m}^{-2}$ ). Active carbon pool has followed a constant decreasing trend from 1850 (289 $\left.\mathrm{g} \mathrm{C} \mathrm{m}^{-2}\right)$ to 2051(36 $\mathrm{g} \mathrm{C} \mathrm{m}^{-2}$ ) and Passive pool of carbon has also followed a constant decreasing trend from 1850 (1667 $\mathrm{g} \mathrm{C} \mathrm{m}^{-2}$ ) to 2051(1135 $\mathrm{g} \mathrm{C} \mathrm{m}^{-2}$ ) (Table 2 and Fig. 5) Regular tillage, planting and harvesting etc. lead to enhanced oxidation of organic matter in soils and is emitted into atmosphere as carbon dioxide (Carroll et al., 2012). Hence the soil organic carbon in cultivated soils is continuing to decline in many areas of the world. However the use of fertilizers, high yielding plant varieties, residue management and reduced tillage for erosion control have found to contribute the stabilization or increase in soil organic carbon (Cole et al., 1993). Like tree plantations, coconut plantations will be efficient for combating climate change as they help in carbon dioxide sequestration in the short term and mitigating atmosphere levels of carbon dioxide in the long term (House et al., 2002). Moreover Organic management of coconut plantation help to attain more efficient soil carbon dynamics which will improve the soil quality as well as yield in sustainable manner.

\section{References}

Batjes, N.H. (1997) Total carbon and nitrogen in soils of world. European J. Soil Sci. 4(7): 151-163.

Carroll, M., Milakovsky, B., Finkral, A., Evans, A., and Ashton, M.S. (2012) Managing carbon sequestration and storage in temperate and boreal forests. 
In: Ashton, M.S., Tyrrell, M.L., Spalding, D and Gentry, B. (eds). Managing Forest Carbon in a Changing Climate. Springer, New York, pp. 205226

Cole, C.V., Flach, K., Lee, J., Sauerbeck., D., and Stewart, B. (1993) Agricultural sources and sinks of carbon. Water Air Soil Pollut. 70(2): 111-122.

Houghton, R. A., Hobbie, J. E., Melillo, J. M., Moore, B., Peterson, B. J., Shaver, G. R., and Woodwell, G. M. (1983) Changes in the carbon content of terrestrial biota and soils between 1860 and 1980: A net release of CO2 to the atmosphere. Ecol. 5(3): 235-262.

House, J.I., Colin Prentice, I., and Le Quere, C. (2002) Maximum impacts of future reforestation or deforestation on atmospheric carbon dioxide. Global change Biol. 8(11):1047-1052.

Katyal, J. C. (2008) Presidential Address deliverd on 27 November in the inaugural function of the $73^{\text {rd }}$ Annual Convention of the Indian Society of Soil Science at University of Agricultural Sciences. J. Indian Soc. Soil Sci. 56(4): 322-324.

Katyal, J.C. (2015) Withering soil science education- Revival and resurgence boosters. J.Indian Soci. Soil Sci. 63(1): 1-13.

Lal, R. (2001) Soil Carbon Sequestration and the Greenhouse Effect. Soil Science Society American special publication, Madison, WI, 236p.

Lal, R. (2008) Soils and India's food security. J. Indian Soc. Soil Sci.25(6):129-138.
Luo Y, Su BO, Currie WS, Dukes JS, Finzi A, Hartwig U et al., (2004) Progressive nitrogen imitation of ecosystem responses to rising atmospheric carbon dioxide. Bioscience 54:731-739

Parton, W.J., D.S. Schimel, C.V. Cole, D.S. Ojima. (1987) Analysis of factors controlling soil organic levels of grasslands in the Great Plains. Soil Sci. Soc. Am. J. 51:1173-1179.

Parton, W.J., J.W.B. Stewart, C.V. Cole. (1988) Dynamics of C, N, P, and S in grassland soils: A model. Biogeochemistry 5:109-131.

Silveira ML, Comerford NB, Reddy KR, Cooper WT, El-Rifai H (2008) Characterization of soil organic carbon pools by acid hydrolysis. Geoderma 144:405-414

Srivastava, P. Singh. R., Tripathi. S., Singh, H. Raghubanshi A.S. (2016) Soil carbon dynamics and climate change: current agro-environmental perspectives and future dimensions.Energ. Ecol. Environ. 1(5):315-322

Swaminathan, M.S. (2008) Growth in Agriculture. Yojana, pp. 40-48.

Trumbore S (2009) Radiocarbon and soil carbon dynamics. Ann Rev. Earth Planet Sci 37:47-66

Vaccari FP, Lugato E, Gioli B, D’Acqui L, Genesio L, Toscano Pet al., (2012) Land use change and soil organic carbon dynamics in Mediterranean agro-ecosystems: the case study of Pianosa Island. Geoderma 175:29-36

\section{How to cite this article:}

Lincy Davis, P., S. Panneerselvam, K.S. Subramanian, S. Sandeep, Balaji Kannan, N. Shoba and Maheswarappa, H.P. 2017. The CENTURY Model as a Tool to Study Soil Carbon Dynamics of Coconut Ecosystem in the Western Zone of Tamil Nadu, India. Int.J.Curr.Microbiol.App.Sci. 6(12): 3467-3476. doi: https://doi.org/10.20546/ijcmas.2017.612.403 